\title{
A Quick and Easy Technique for Lateral Canthoplasty Using Reverse V-Y Advancement: A Case Report
}

\section{Jae Yeon Park, Hyo Joong Kim, Seil Lee, Sung Gyun Jung}

Department of Plastic and Reconstructive Surgery, National Medical Center, Seoul, Korea

No potential conflict of interest relevant to this article was reported.

\begin{abstract}
Cosmetic lateral canthoplasty has become popular among Asians in the last few decades, but few techniques have withstood the test of time to be accepted as both effective and noninvasive, with minimal complications. Novel techniques have been developed, but are not free from complications. Moreover, these methods often have limited indications and may require a rather long learning curve to master. Herein, the authors present their experiences performing a simple lateral canthoplasty procedure in 61 patients using a slightly modified $\mathrm{V}-\mathrm{Y}$ advancement flap, previously known as the Uchida method.
\end{abstract}

Keywords Anatomy regional, Blepharoplasty, Cosmetic techniques

\section{INTRODUCTION}

Cosmetic lateral canthoplasty is quite commonly performed in Asian patients, in a manner fundamentally different from the canthoplasty procedures performed in Caucasians. Caucasians may undergo lateral canthoplasty at a relatively older age than Asian patients. Asians have a shorter horizontal dimension of the palpebral fissure [1] than their Caucasian counterparts. Moreover, Asians tend to have upslanting of the palpebral fissure in comparison to Caucasians. In other words, the angle between the medical canthus and the lateral canthus has a higher inclination $\left(7.9^{\circ} \pm 2.4^{\circ}\right.$ in men and $8.8^{\circ} \pm 2.3^{\circ}$ in women). In recent decades, Asians, including the younger generation, have exhibited an ever-increasing interest in undergoing cosmetic lateral canthoplasty. Even plastic surgeons who exclusively perform cosmetic surgery have only recently started to perform cosmetic lateral canthoplasty actively, commensurate with the unprecedented growth in demand. In the context of the increasing demand for this procedure, we report our experiences with a simple and easy procedure consisting of a modifica-

Received: Sep 28, 2017 Revised: Nov 23, 2017 Accepted: Nov 23, 2017 Correspondence: Seil Lee Department of Plastic and Reconstructive Surgery, National Medical Center, 245 Eulji-ro, Jung-gu, Seoul 04564, Korea. E-mail: leeseil.nmcps@gmail.com

Copyright @ 2018 The Korean Society for Aesthetic Plastic Surgery.

This is an Open Access article distributed under the terms of the Creative Commons Attribution Non-Commercial License (http://creativecommons.org/licenses/by-nc/4.0/) which permits unrestricted non-commercial use, distribution, and reproduction in any medium, provided the original work is properly cited. www.e-aaps.org tion of the Uchida method.

\section{CASE REPORT}

\section{Patients}

From March 2012 to October 2016, 61 patients underwent lateral canthoplasty. The follow-up period ranged from 3 months to 2 years, with an average follow-up period of 7 months.

\section{Preoperative evaluation}

Of the 7 items on the lower eyelid checklist proposed by Tepper et al. [2], the canthal tilt and lateral canthal orbital rim (distance from the lateral canthus to the orbital rim) [3] can be assessed before undertaking cosmetic lateral canthoplasty. This preoperative evaluation is performed by many plastic surgeons (Fig. 1).

\section{Operative technique}

While the first assistant pulled the lateral aspect of the palpebral fissure in an outward lateral direction, a marking was made after measuring a point $5 \mathrm{~mm}$ from the lateral end of the lateral canthus (the end of the palpebral fissure). Traction sutures were made at the upper and lower eyelid margins $(5-10 \mathrm{~mm}$ from the lateral canthus) with 4-0 Vicryl. Local anesthesia consisting of $0.5 \mathrm{~mL}$ of a mixture of $2 \%$ lidocaine with epinephrine $(1: 1,000)$ was infiltrated into the design area. Using a No. 11 Bard-Parker blade, an incision was made from the medial to lateral aspect along the gray line. Using Metzenbaum scissors, the incision was furthered medially by about $3 \mathrm{~mm}$, so that the palpebral conjunctiva was dissected. Undermin- 

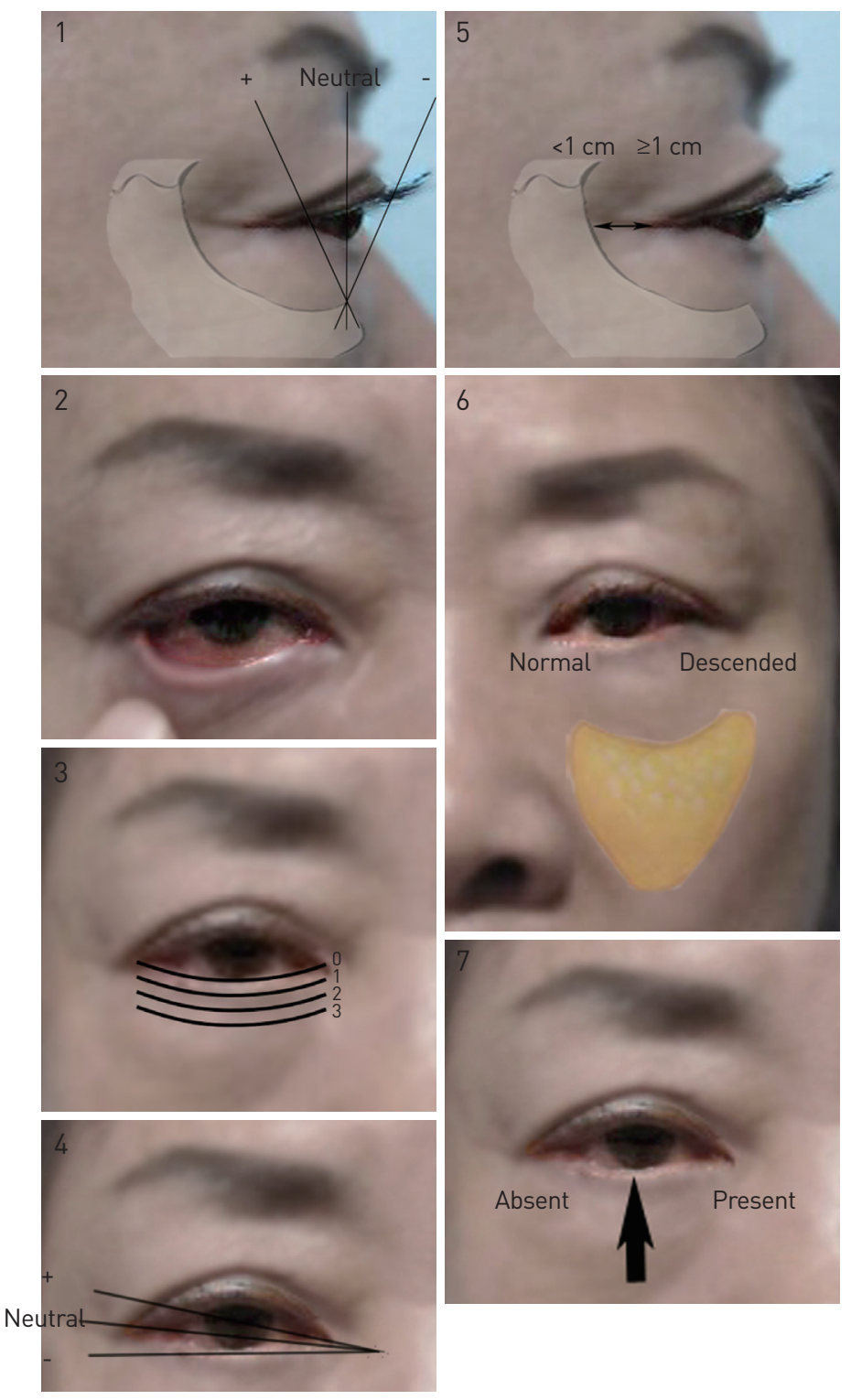

Fig. 1. The 7 step checklist helps surgeons approach lower eyelid procedures in a standardized fashion. ing was done using blunt tenotomy scissors, and was performed thoroughly in the upper lateral and lower lateral directions to ensure full liberation of the reverse V-Y flap. Meticulous hemostasis and orbicularis oculi muscle dissection were carried out with a Bovie electrocoagulator. When the dissection was completed, even though the palpebral conjunctiva incision was only $3 \mathrm{~mm}$, the flap could be advanced by $5 \mathrm{~mm}$ because of the different viscoelastic properties between the conjunctiva and the gray line; in particular, the gray line has less elasticity than the conjunctiva. Anchoring sutures serving both fixation and traction purposes were placed at 5 points, using 5-0 black silk sutures. They were tethered to contiguous skin using Steri-Strips in a fold-over-fold fashion so that each suture was fixed with 3 interlocking Steri-Strip tapes stacked onto each other, folding onto itself in opposite directions. The traction sutures remained in place for 10 to 14 days, and only the Steri-Strips were replaced after cleansing the operative site at intermittent follow-up visits (Fig. 2).

\section{Postoperative care}

After surgery, oral antibiotics and an ophthalmic ointment consisting of a mixture of antibiotics and a steroid were prescribed. The sutures and Steri-Strips were removed at 10 days postoperatively. Patients were not allowed to rub their eyes for a month, and facial cleansing and showering were allowed after the stitches were removed.

\section{DISCUSSION}

Three points are worth mentioning in terms of the advantages of the Uchida surgical technique. The first important advantage of the reverse V-Y advancement lateral canthoplasty is its simplicity. Given the easy and straightforward nature of the technique, the learning curve can be as short as a few weeks. Any board-certified plastic surgeon, and perhaps even non-board certified surgeons, can grasp the notion of the V-Y advancement flap, and since this procedure involves only a minor modification of this flap, a long time
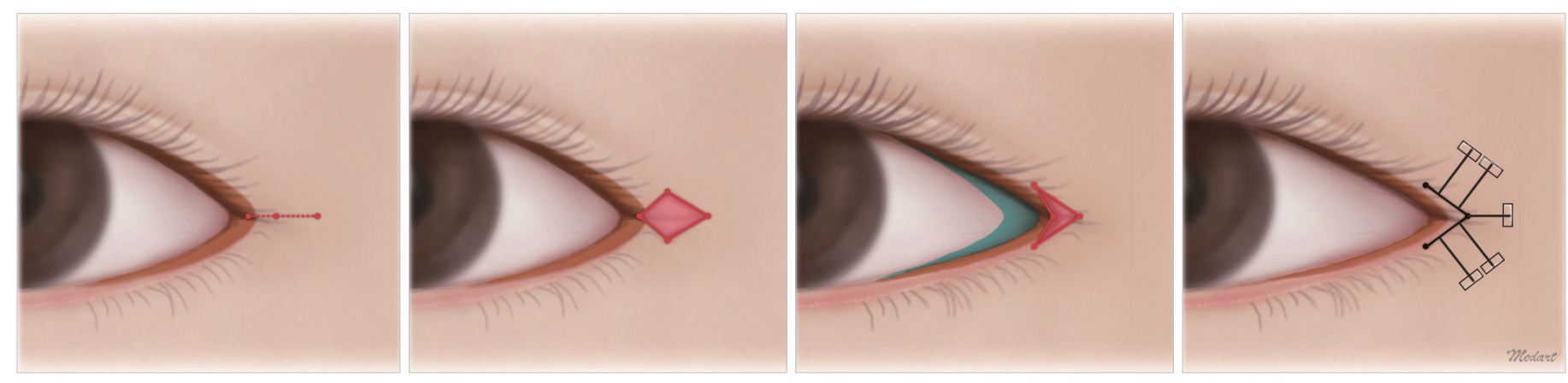

Fig. 2. Schematic illustration of reverse V-Y advancement lateral canthoplasty. 

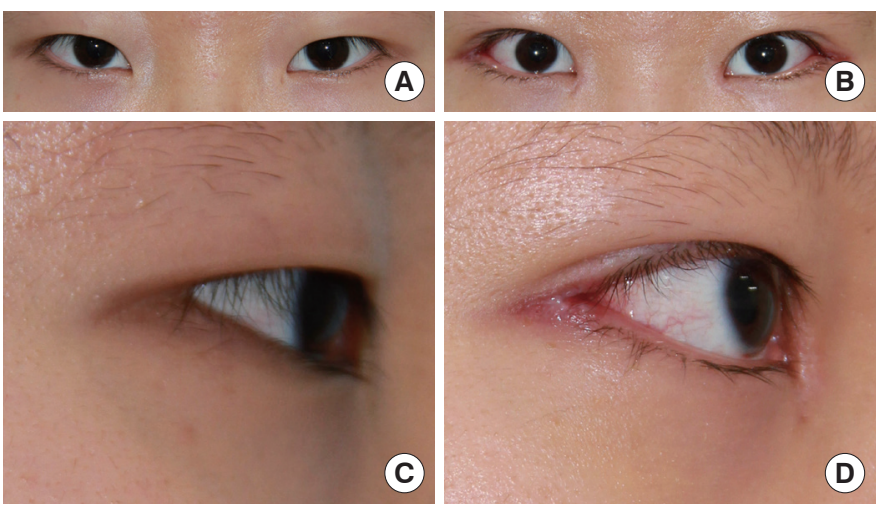

c
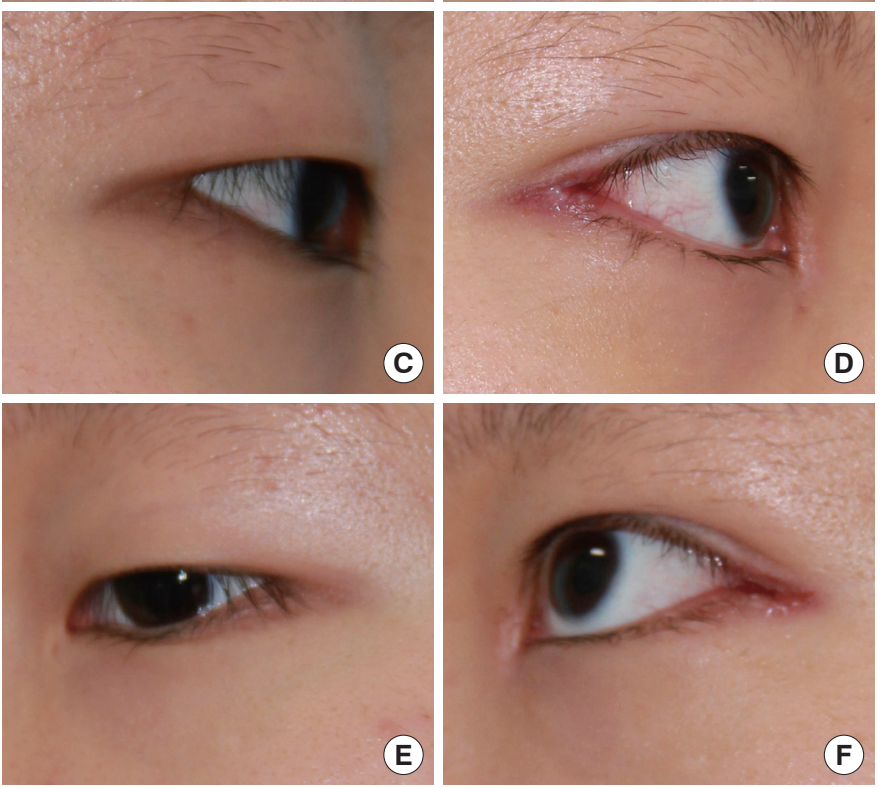

Fig. 3. Photographs of a 21 -year-old female patient. Lateral canthoplasty and double eyelidplasty were performed. (A, C, E) Preoperative photographs. (B, D, F) Photographs 3 months postoperatively.

is not necessary to master it. The second advantage is how quickly the procedure can be performed. Because the technique does not employ cantholysis or canthopexy, the lateral canthal angle is well preserved. Hence, it is a quick surgical procedure that requires on average 15 to 20 minutes bilaterally. Most conventional techniques employ the rather invasive techniques of canthotomy or cantholysis [3], which may be difficult for beginner surgeons, potentially making it more difficult to address complications in secondary cases. In addition, when the distance between the lateral canthus and the lateral orbital rim was less than $4 \mathrm{~mm}$, cosmetic lateral canthoplasty was complicated. However, in our experience, it is worth trying this procedure using a reverse $\mathrm{V}$-Y flap, as we have performed such a procedure in a patient who reported satisfaction (Fig. 3).

According to Shin and Hwang [4], surgery tends to be less effective when there is a small amount of space between the lateral canthus and the lateral bony orbital wall. Moreover, a distance of more than $4 \mathrm{~mm}$ should be observed from the orbital rim to the lateral canthal angle in exophthalmometry $[1,2,4]$. The canthal tilt assessment has been proposed by Tepper et al. [2] as 1 of 7 steps in the lower eyelid checklist. However, this parameter is not as important when lateral canthoplasty is performed following the present authors' technique. Instead, the lateral canthal inclination relative to the coronal plane is important. Canthal tilt refers to the inclination that measures how high the lateral canthus is in relationship to the medial canthus by comparing an imaginary line connecting the

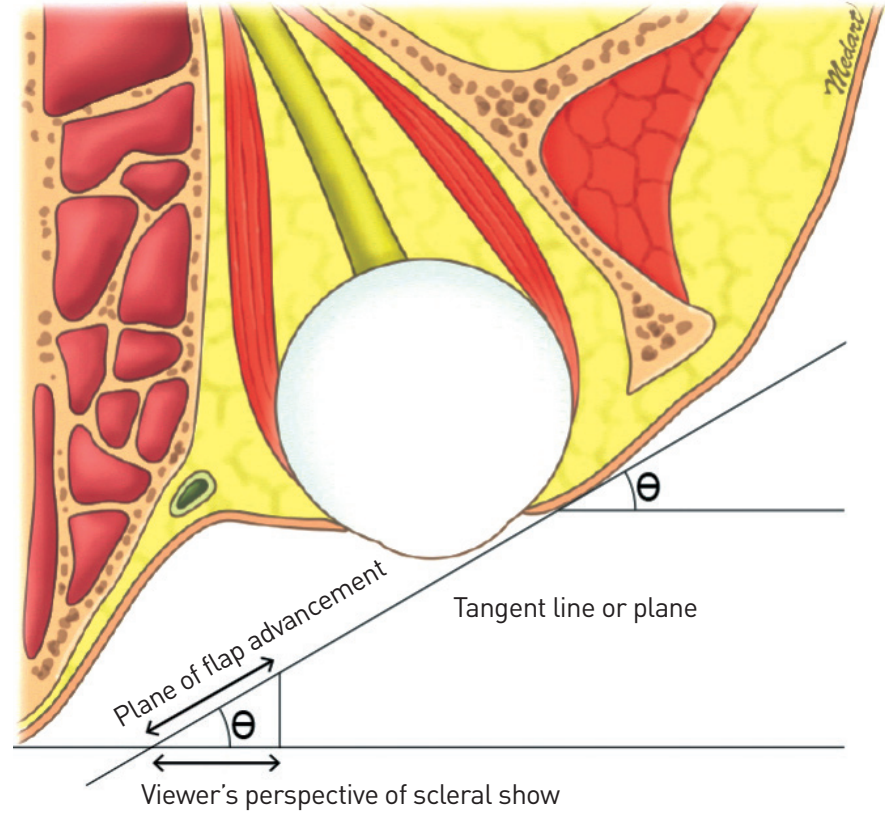

Fig. 4. Illustration of lateral canthal inclination: the angle between a plane that is tangent to the eyeball at the point of the lateral commissure and the plane that is tangent to the center of the cornea in a coronal plane.

lateral canthus and the medial canthus with an imaginary horizontal line penetrating the medial canthus. The lateral canthal inclination is the angle between a plane that is tangent to the eyeball at the point of the lateral commissure and the plane that is tangent to the center of the cornea in a coronal plane. This indicates how posterior the lateral canthus is in relation to the outermost point of the eyeball. The further it is away from the center point, the less effect it will have on the surgical results (as in exophthalmos patients), and vice versa (Fig. 4).

In conclusion, reverse $\mathrm{V}$-Y advancement lateral canthoplasty is a quick and easy method that can be applied to a wide spectrum of patient groups. It can especially be useful for young patients who hope to undergo double eyelidplasty, medial epicanthoplasty, and lateral canthoplasty with vertical lengthening at the same time.

Because of the simplicity and short learning curve of reverse $\mathrm{V}-\mathrm{Y}$ advancement lateral canthoplasty, this procedure is suitable for more junior surgeons. However, since our average follow-up period was only 7 months, with the longest follow-up period being 2 years, long-term observations are needed to demonstrate the effectiveness of reverse V-Y lateral canthoplasty.

\section{PATIENT CONSENT}

Patients provided written consent for the use of their images. 


\section{REFERENCES}

1. Chae SW, Yun BM. Cosmetic lateral canthoplasty: lateral canthoplasty to lengthen the lateral canthal angle and correct the outer tail of the eye. Arch Plast Surg 2016;43:321-7.

2. Tepper OM, Steinbrech D, Howell MH, et al. A retrospective review of patients undergoing lateral canthoplasty techniques to manage exist- ing or potential lower eyelid malposition: Identification of seven key preoperative findings. Plast Reconstr Surg 2015;136:40-9.

3. Kim YJ, Lee KH, Choi HL, et al. Cosmetic lateral canthoplasty: preserving the lateral canthal angle. Arch Plast Surg 2016;43:316-20.

4. Shin YH, Hwang K. Cosmetic lateral canthoplasty. Aesthetic Plast Surg 2004;28:317-20. 